\title{
Espacios de arte y cultura en los Centros de Desarrollo Comunitario (CDC)*
}

\section{Puntos de partida}

La gestión social en los museos es un área en desarrollo dentro de la museología, que en su centralidad busca la vinculación con diversos públicos y la generación de estrategias de trabajo diversas que posibiliten no sólo llegar a los otros, sino establecer una relación dialógica e interactiva en la cual aprehendemos y compartimos saberes.

El punto de partida de la propuesta tiene, como una de sus bases, la concepción contemporánea del museo, según la cual éste no se limita a coleccionar objetos y organizar exposiciones, sino también a ejecutar acciones de participación social y apropiación del territorio.

La plataforma educativa y conceptual del trabajo planteado en el territorio, y más concretamente en los CDC, se remite a la propuesta educativa de los museos como espacios no formales de la educación, en donde se conjugan las propuestas de cada persona con las propuestas del museo, manifestadas en su propia forma y en el potencial de acercarse al conocimiento, construirlo y generar un saber propio (tal como señalara Howard Gardner a través de la teoría de las inteligencias múltiples).

La necesidad denotada en educadores y educandos de que el conocimiento pueda ser trasladado a contextos propios y personales; la importancia, por tanto, de un aprendizaje significativo del cual tenemos como referente a Ausubel; los contextos personales, familiares y sociales que son parte del proceso de aprendizaje y la construcción social del conocimiento como aporte vygotskiano, nutren al museo y son aportes al campo de gestión y vinculación social. Sin embargo, la principal propuesta educativa es la de considerar a la educación y a las teorías educativas desde una liquidez que permita al educador adaptarse a los educandos e ir construyendo con ellos un modelo propio de trabajo, focalizado en su proceso particular.

* Espacios de arte y cultura en los Centros de Desarrollo Comunitario (CDC), es un proyecto de Gestión Social y Educación, de la Fundación Museos de la Ciudad (FMC) dirigido a los CDC de Quito.

** Sandra Castillo psicóloga, maestrante en Educación por el Instituto Tecnológico de Monterrey. Es responsable del área de Gestión Social Educativa de la Fundación Museos de la Ciudad (FMC). 
En el presente proyecto, además de las teorías en educación como tales, se sumó otro eje transversal, necesario y definitorio, para los fines planteados: la participación ciudadana como la búsqueda del ser, es decir, tomar y tener parte en cada paso del proceso planteado.

Hablar de participación de la ciudadanía implica remitirnos a diferentes cosas de acuerdo a la persona o grupo de personas. En este proceso en particular haremos referencia a la propuesta teórica sobre participación de Trillas y Novella, quienes, a partir de la escala de Arnstein, definieron cuatro escalas de participación más amplias, que a su vez son cuatro maneras de participar cualitativa y fenomenológicamente distintas, es decir, cada una se define en sus propios términos y a su vez puede tener gradientes; además, su definición está sujeta a variables tales como: implicación, capacidad de decisión, responsabilidad, etc.

Dado que esta escala de participación supone varias formas diferentes de ser parte de un proceso -como el planteado desde la FMC hacia los CDC-, la elección de esta denominación en formas y niveles de participación nos remite, más que a una cuantificación, a una cualificación de lo que significa formar parte de un proceso con pautas directivas prediseñadas desde la institución, los talleristas o las organizaciones comunitarias. Así, se considera que sí es posible el acercamiento para acceder a otra mirada en cada uno de los pasos propuestos.

Trillas y Novella definieron los tipos de participación como:

Participación simple. Nos remite a tomar parte en un proceso o actividad, ya sea como espectador o ejecutando la actividad como tal, sin que esta previamente haya sido preparada o decidida por el participante.

Participación consultiva. Supone escuchar la palabra del otro, partícipe o actor de un proceso; sin embargo, la consulta como tal no remite, de hecho, a tomar en cuenta los aportes obtenidos. En este tipo de participación, como en los otros, puede existir una diversidad de variables que van desde una simple encuesta -que a su vez termina fungiendo como un medio más cuantitativo que cualitativo de participación- hasta una retroalimentación que permite cambiar el curso de un proceso o actividad planteado.

Participación proyectiva. Remite a no ser 'usuario' de un proceso, sino a ser 'agente' del mismo. Se refiere a una apropiación de lo que se hace en cuanto a fines objetivos y valoraciones afectivas y emocionales.

Metaparticipación. Supone una participación pedida, exigida o generada desde la ciudadanía. Aquí el objeto de la participación es la propia participación.

Los mismos autores también señalan parámetros que es necesario mencionar, pues permiten establecer gradaciones en los tipos de participación, a medida que se combinan y entrecruzan:

- implicación

- conciencia/información

- capacidad de decisión

- compromiso/responsabilidad

\section{Propuesta metodológica}

Partiendo de las premisas y bases de las teorías educativas y de su liquidez y adaptabilidad al entorno comunidad, así como de la participación como un eje transversal sujeto a revisión y retroalimentación constante, debemos situar la mirada en la metodología como tal yen su abordaje.

Las primeras aproximaciones hacia las comunidades se dieron con el acompañamiento del artista Pablo Sanaguano, quien propició ejercicios de interacción con los participantes a través de diversas sesiones de diálogo y aprendizaje, para realizar un análisis sobre lo que la comunidad quiere compartir.

Con este acercamiento fue posible recabar información sobre los requerimientos propios de cada escenario, lo que a su vez permitió estructurar -bajo un esquema pedagógico cons- 
tructivista- la participación de los habitantes de las distintas comunidades, apoyados por facilitadores que los acompañaron en sus procesos, aplicando métodos educativos no formales $y$ usando herramientas de las artes plásticas, visuales y escénicas.

Este primer abordaje metodológico buscaba reconocer al 'otro' y en ese 'otro' reconocer el trabajo propio. Un trabajo definido desde el espacio contextual, físico y social de cada uno de los 15CDC partícipes de la primera etapa, y desde los que se fueron sumando al proceso a partir del año 2010.

El proyecto piloto culminó en febrero de 2011 con la exposición "Quince travesías", que exhibió procesos y productos desarrollados en cada una de las comunidades y barrios participantes.
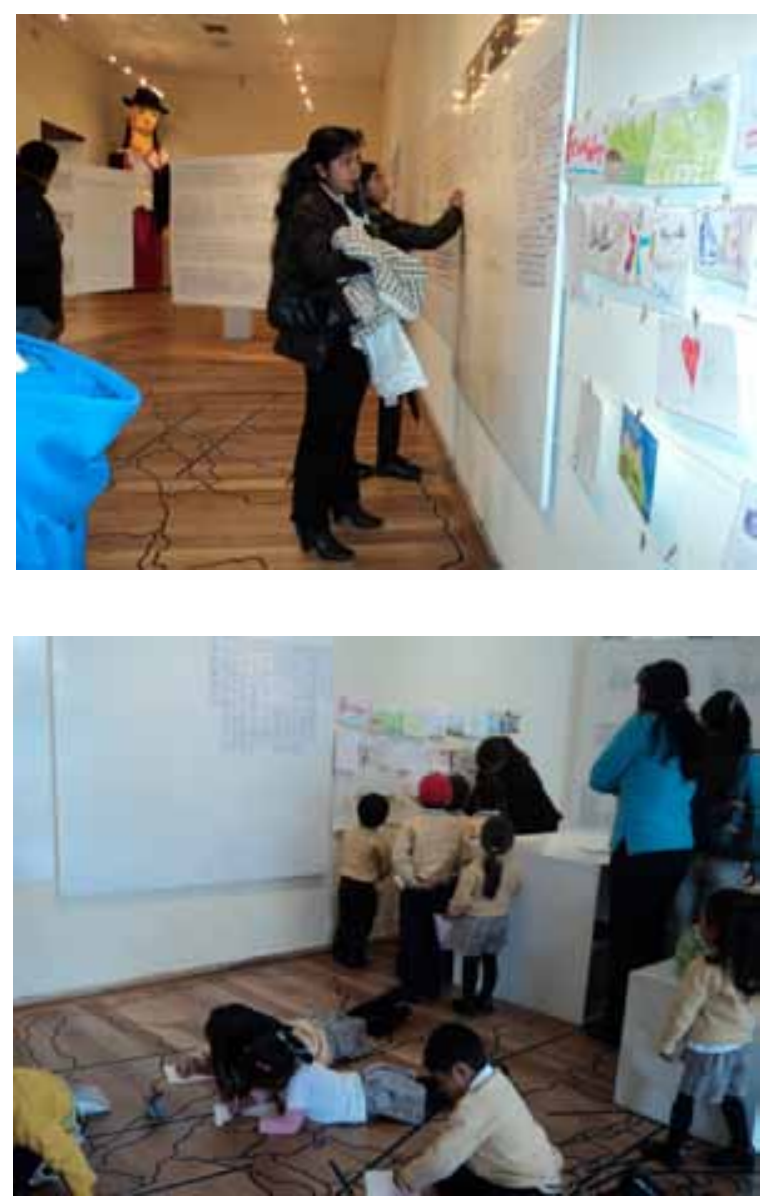

La exhibición fue tan diversa como cada uno de los procesos desarrollados y su finalidad fue resaltar el valor de la diversidad de las miradas de los participantes. Esta primera fase fue un acercamiento inicial a través de encuentros de participación comunitaria donde se compartieron saberes. Algunas veces fue necesario redefinir y replantear una mirada para sumarla al diálogo conjunto de los participantes en cada espacio, se debieron sumar más voces, practicar la escucha activa y generar consensos y a veces también disensos.

Los barrios y parroquias de Quito que participaron en este proceso son:

- Alangasí

- Amaguaña

- Conocoto

- Cotocollao

- Chavezpamba

- Ferroviaria Alta

- Guangopolo

- IESS-FUT

- La Tola

- Nayón

- Puembo

- San Diego

- San Marcos

- Yaruquí

- Zámbiza

\section{Mapa de los quince barrios}

Las comunidades que decidieron participar en estos encuentros de labor conjunta trabajaron en procesos de reflexión y levantamiento de información relacionada con su memoria y los elementos significativos e identitarios de su entorno, para utilizarlos como componentes de su producción y para asimilar de su contexto los aspectos más valiosos que pueden ser representados en nuevos lenguajes. Así, el fin era dejar 
esta producción como legado a la familia, los vecinos y las generaciones venideras.

Los participantes fueron testigos de que la memoria puede ser revalorada y puede constituirse como uno de los elementos primordiales del patrimonio cultural. Cada testimonio, recuerdo, anécdota, mito, leyenda, etc. fue uno de los ingredientes básicos de una receta indefinida y variable, donde ha sido posible inmiscuirse en un ámbito de producción artística desde el corazón de cada barrio.

El acompañamiento que la gente tuvo por parte de los facilitadores-artistas proporcionó algunos conocimientos técnicos, metodológicos y de gestión que, sumados a una sabiduría inherente a estos 15 escenarios, confluyeron en un bagaje ampliamente enriquecido por lo oral, lo gestual y lo plástico. En cada una de las pinceladas y en los ejercicios desarrollados se puede reconocer una producción apegada a la identificación de las raíces, porque es a partir de ellas que se potencian las virtudes y se perfeccionan los elementos que deben mejorar y fortalecerse. Es así que cada uno de los miembros de las comunidades, que aceptaron la invitación para participar de los talleres, fueron protagonistas de cada proceso, marcando los ritmos de acción de acuerdo a sus necesidades específicas.

Se puede reconocer que la riqueza de este proceso radica, sobre todo, en los puentes que se han extendido para generar un diálogo entre las comunidades y la institucionalidad, pues ahora que los lazos han sido tendidos, será meta de proyectos venideros fortalecer dichas alianzas.

\section{Los resultados 2010 en imágenes}

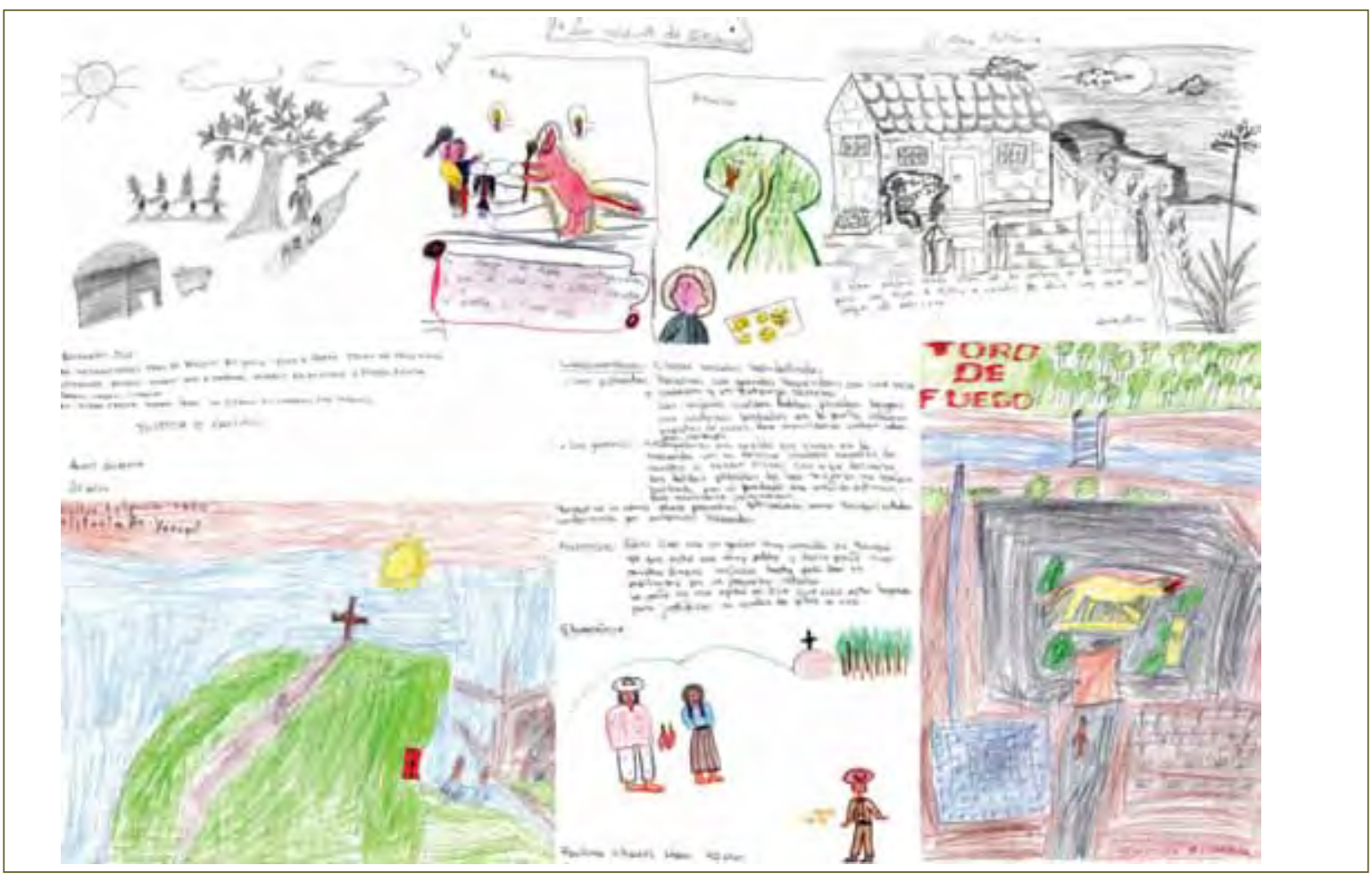

Imagen para libro "Entre duendes, leyendas y hierbas medicinales yaruqueñas" 


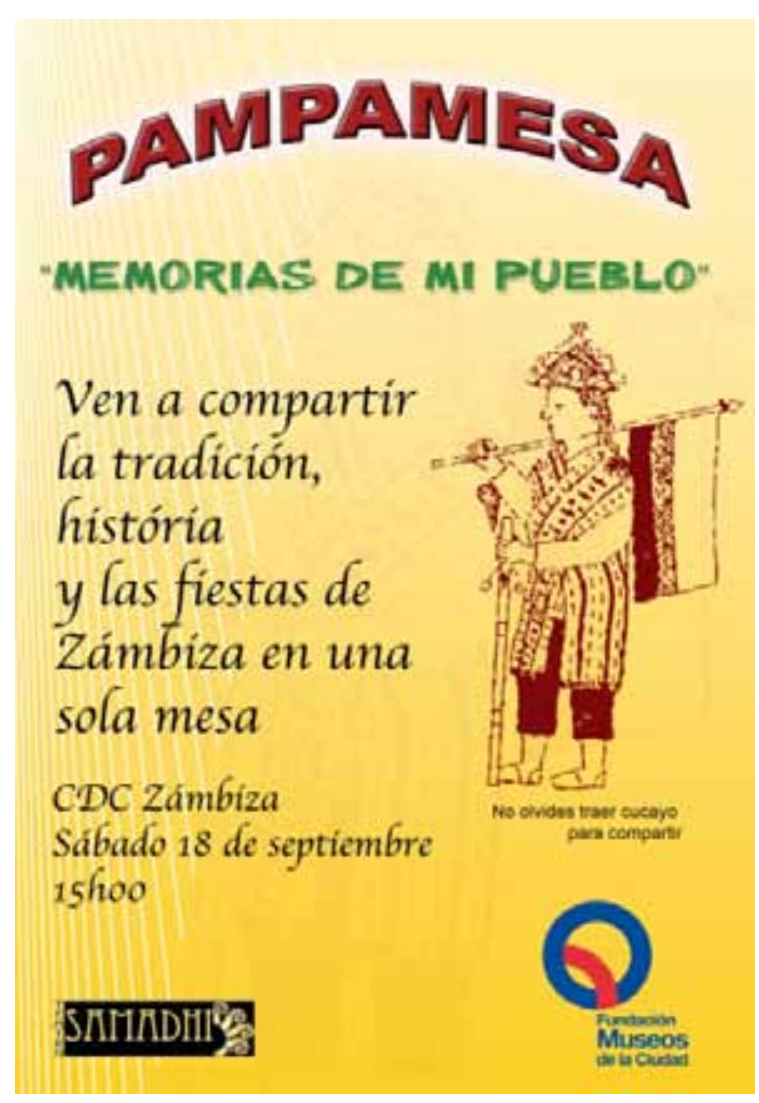

Los resultados 2011

Como proceso en construcción, las temporalidades de los talleres y eventos han tenido la doble marcación de los tiempos de la institución y de las comunidades involucradas. Así, durante 2011 se desarrollaron talleres y actividades encaminadas a consolidar el proceso del año anterior, así como a generar nuevos diálogos desde el arte, la cultura y los museos, como herramientas y espacios de construcción social y ciudadana.

Durante 2011 el proyecto se ejecutó en tres niveles:

- museos de la FMC y sus actividades culturales

- promotores y de coordinadores zonales

- usuarios de los CDC

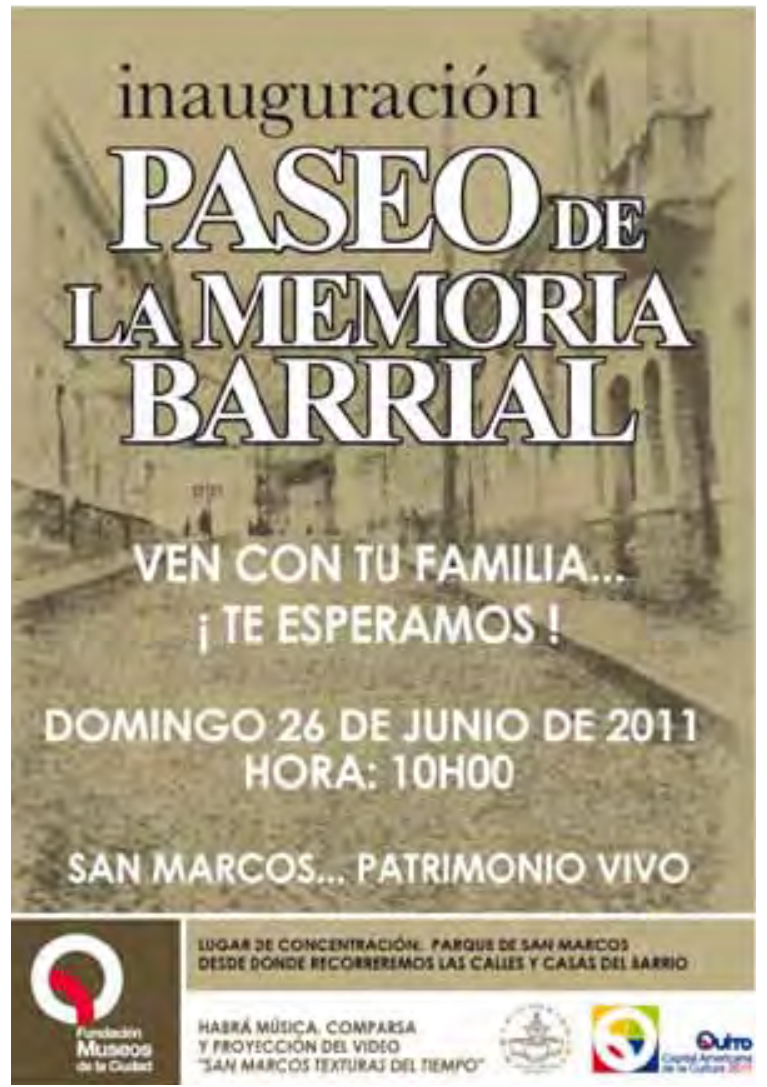

Afiche para la inauguración de las placas sobre la memoria del barrio San Marcos

El primer nivel llevó a desarrollar actividades de reconocimiento mutuo en cuanto a haberes y saberes tanto desde la FMC como desde los barrios y parroquias participantes en el proceso. De allí partieron las invitaciones tanto de los museos para ser visitados como desde los CDC para participar en los eventos y actividades. Esto incidió en el incremento del número de visitantes a los museos desde las parroquias (grupos de mujeres, adultos mayores, escuelas, etc.) y en la participación en actividades culturales y educativas como el "VIII encuentro CECA: Museos, educación y buen vivir".

En el segundo nivel, contemplado en coordinación con la Secretaria de Territorio, se preparó un proceso de capacitación con los promotores en cuanto a la gestión realizada 
desde sus áreas de trabajo, para potencializar las actividades desarrolladas y la labor conjunta de la FMC y la Secretaría de Territorio.

En cuanto al tercer nivel, en los CDC se han ejecutado los siguientes proyectos:

CDC Zámbiza. Se está desarrollando un trabajo desde la mirada de la memoria agrícola de la parroquia. El tema propuesto fue "Revivir los conocimientos acerca de la agricultura local". El grupo participante está trabajando en un huerto cercano al CDC y documentando de manera visual los saberes y la memoria de sí mismos, en especial de los adultos mayores del sector.

Se prevé concluir el trabajo con una presentación del trabajo realizado, la edición en video de la memoria de los adultos mayores y la difusión de los saberes a través de medios radiales.

CDC Nayón. Se desarrolló un taller con jóvenes para recopilar saberes en torno a los juegos tradicionales. La acción ha sido denominada "Recopilar la memoria de Nayón acerca de los juegos típicos".

El taller, que concluyó en enero de 2012, preveía la preparación de un espacio para exponer y difundir, tanto en la parroquia como en la ciudad de Quito, el trabajo realizado.

CDC Mangahuantag. El grupo, conformado en su mayoría por mujeres y niños, ha decidido abordar el tema del patrimonio para "generar un espacio de participación colectiva en la producción artística y promover el desarrollo de la creatividad y la imaginación".

CDC Chavezpamba. Se organizaron talleres de memoria, patrimonio e identidad a través del arte. Se trata de un grupo intergeneracional que aborda el tema del patrimonio como una búsqueda de espacios de participación colectiva para la producción artística y la promoción de la creatividad.

CDC Yaruquí. Se formó un grupo intergeneracional con el que se ha decidido abordar el tema del patrimonio para "desarrollar un proceso de trabajo acerca de los valores culturalesidentitarios de Yaruquí: tanto de los que están presentes en el día a día, como de los que necesitan ser recuperados y/o promovidos".

Este grupo se ha preparado también en narración y lectura, actividad con la que se espera arrancar en 2012 una serie de jornadas en las que, a través de la recopilación de saberes y memoria, llegarán a escuelas, instituciones educativas y medios de prensa con sus relatos.

CDC Guangopolo. Es un grupo, en su mayoría de adultos, que ha venido trabajando en el tema del patrimonio para "desarrollar un proceso de trabajo acerca de los valores culturalesidentitarios de Guangopolo que permitan hacer una recopilación de información para el segundo número de la revista 'Mirando el barrio'. La revista de Guangopolo".

CDC Alangasí. El grupo piloto de este CDC está conformado por jóvenes que han decidido abordar el tema del patrimonio para "desarrollar un proceso de trabajo acerca de los valores culturales-identitarios de Alangasí que permita hacer una recopilación de información en audio y video para la creación de un video".

CDC Carcelén Bajo y Cotocollao. En la administración zonal La Delicia, en la que se encuentran estos CDC, se realizó en 2010un trabajo en red a través de la danza y los saberes de sus grupos de arte. Para el año 2011 -tomando como sede el CDC Carcelén Bajo- se desarrolló una escuela piloto de formación de gestores culturales comunitarios, cuyos módulos fueron diseñados desde las necesidades de los grupos y tomando como base las escuelas de gestión cultural existentes.

Los cursos de capacitación contemplan la gestión del arte, cultura y producción de eventos comunitarios, y están dirigidos a representantes de colectivos artísticos especializados en danza pertenecientes al sector de Carcelén Bajo y Cotocollao.

CDC San Diego. Tomando como base el trabajo desarrollado con el grupo de marmoleros del sector y su interés por continuar generando actividades conjuntas, se han desarrollado en este 
CDC las sesiones de trabajo para definir el camino a seguir, los temas y planes a futuro del grupo.

Se prevé, con la autorización de la responsable de la administración zonal Centro, la colocación en el nuevo CDC-ahora en construcción-de las esculturas en mármol trabajadas con la FMC durante 2010. Se iniciará, además, un proceso de trabajo en medios audiovisuales que permita la vinculación de la comunidad en pleno y la difusión hacia el resto de la ciudadanía.

CDC San Marcos. Siguiendo la pauta del año 2010 de recabar información sobre memoria e identidad de los primeros habitantes del barrio, en 2011 se continuó con ese proceso y se preparó, además, un taller de radiodifusión para conocer y compartir la mirada que los jóvenes y adolescentes tienen sobre su barrio. Una actividad que permitió contrastar diversos puntos de vista e integrarlos a la construcción de San Marcos.

Admin. Zonal Quitumbe. Esta administración zonal no fue parte del trabajo, pero con ellos se prevé la realización de un trabajo conjunto sobre sus intereses y consumos culturales, a través del cual podremos, conjuntamente con los CDC del sector y sus usuarios, definir los temas a tratarse; de allí que la FMC realizará hasta mayo de 2012 una cartografía de consumos en el sector.

Admin. Zonal Calderón. El trabajo en esta administración no se realizó en 2010 y para 2011, a través de una vinculación con la Secretaría de Educación, se desarrollaron actividades que involucraron a los gestores culturales de la administración como capacitadores de las escuelas de los circuitos educativos.

Dicha actividad ha permitido generar talleres de trabajo sobre educación no formal con los gestores que desarrollan actividades en los CDC.

CDC Conocoto. Este grupo está en proceso de trabajo. A él asisten jóvenes y adultos cuyas herramientas son de índole visual, pues tienen la idea de producir vídeos sobre Conocoto, empezando con la hacienda San José.

CDC Amaguaña. El grupo piloto de este CDC está conformado en su mayoría por mujeres jóvenes y adultas, quienes han decidido abordar el tema del patrimonio desde los lugares representativos de Amaguaña. El soporte de su trabajo serán las fotografías, con las que intentan capturar otras miradas sobre su parroquia.

\section{El trabajo desarrollado en cifras}

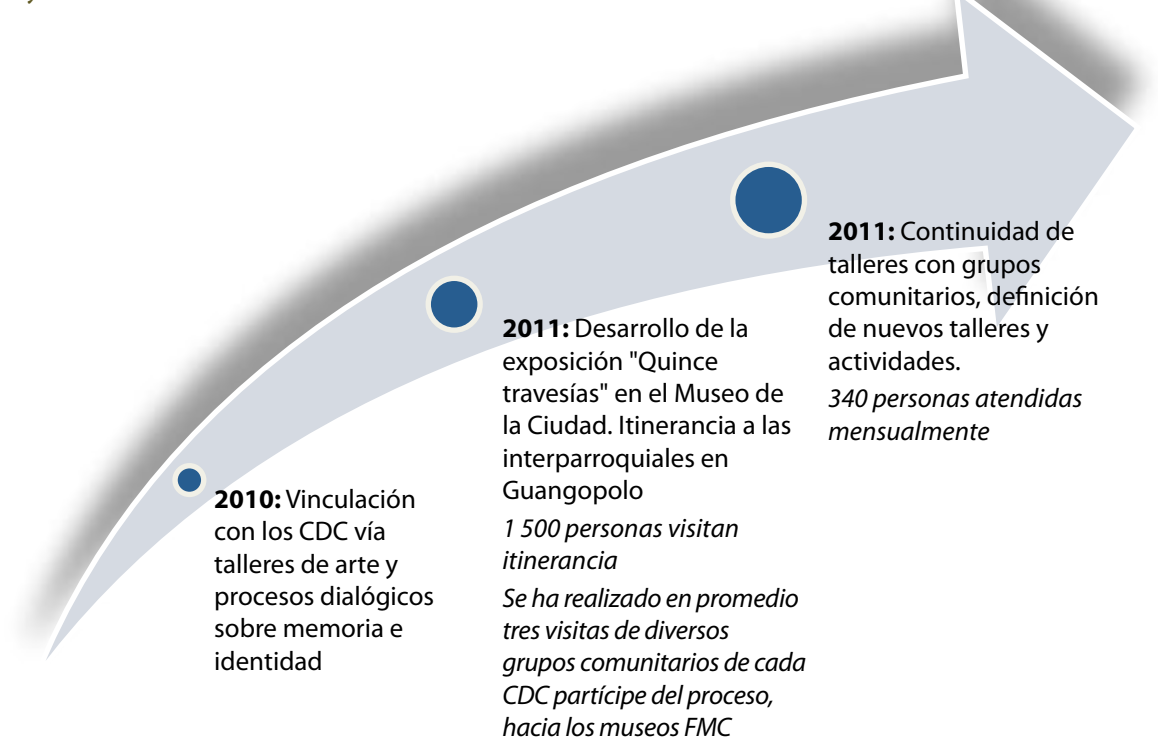




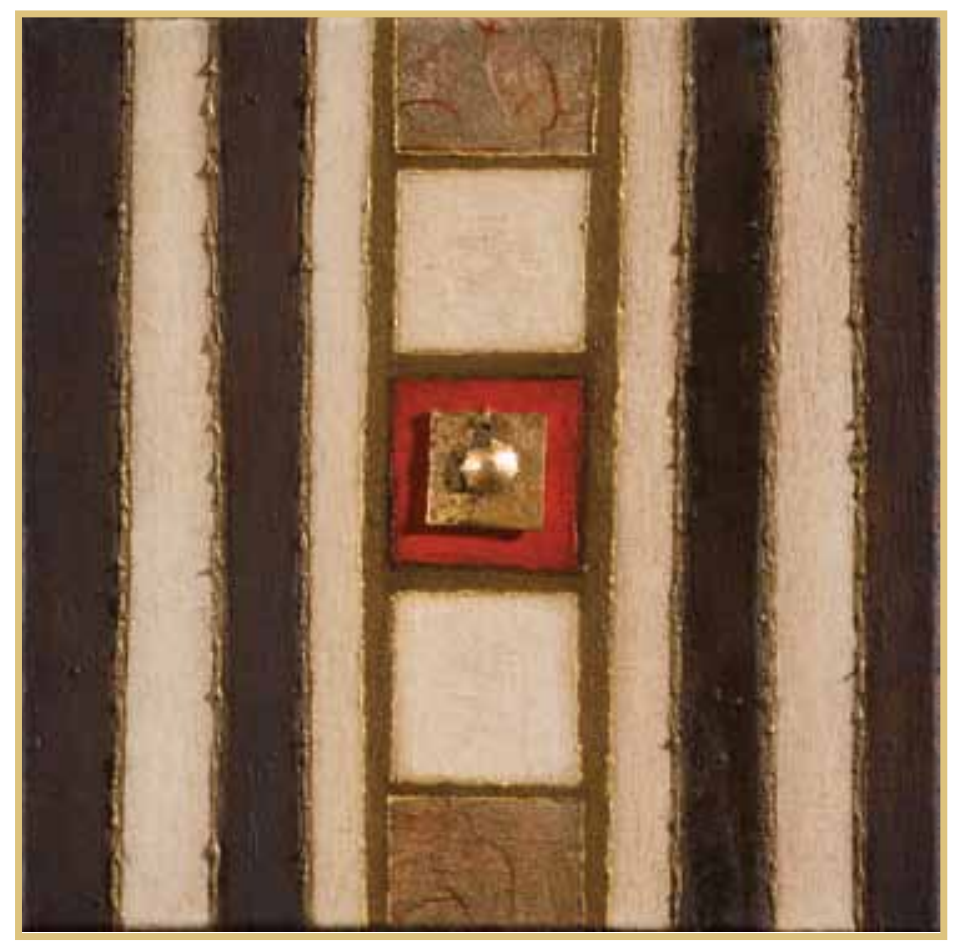

Unitario - 2010

$20 \times 20 \mathrm{~cm}$

\section{Conclusiones}

El trabajo desarrollado en torno a los CDC a partir del año 2010 ha sido y sigue siendo una oportunidad de replantearse la mirada hacia lo público y los públicos, desde el museo como institución. Un replanteamiento que implica preguntarse hacia dónde miramos o pensamos en el ejercicio de diseñar y realizar proyectos.

$\mathrm{Y}$ aunque el proceso aún no ha culminado, consideramos que, desde el quehacer cultural, son estos los insumos que permiten redefinir la gestión del museo. El proceso del presente año tendrá como objetivo continuar la búsqueda y desarrollo de herramientas comunicacionales, partiendo de la definición conjunta de procesos, prioridades y porqués de cada barrio o comunidad.

Este proceso dialógico, por tanto, saldrá, en 2012, de una relación 'museos/ comunidades/barrios participantes' a una integración al imaginario simbólico y real del Distrito Metropolitano de Quito.

\section{Bibliografía}

- GARDNER, Howard, La inteligencia reformulada, Ed. Paidós, Madrid, 2001.

- MAYER, Richard, Psicología de la educación, ensenar para un aprendizaje significativo, Ed. Pearson Educación, Madrid, 2004.

- JAIR VEGA, Manuely GARCÍA, Luz, "Imaginarios de ciudadanía en niños y niñas: ¿súbditos o empoderados?", en: Investigación y desarrollo, vol. 13, No. 2, 2005. 